\title{
Cadmium-Sensitive Measurement Using a Nano-Copper-Enhanced Carbon Fiber Electrode
}

\author{
Jian Wu ${ }^{1, \dagger}$, Zhipeng $\mathrm{Xu}^{2,+}{ }^{\dagger}$, Xian Wang ${ }^{3}$, Li Wang ${ }^{1, *}$, Huadong Qiu ${ }^{1}$, Kechao Lu ${ }^{1}$, \\ Wenhong Zhang ${ }^{1}$, Qing Feng ${ }^{4}$, Jun Chen ${ }^{1, *}$ and Lei Yang ${ }^{5, *(D)}$ \\ 1 School of Mechanical \& Automotive Engineering, Qilu University of Technology (Shandong Academy of \\ Sciences), Jinan 250353, China; 1043118197@stu.qlu.edu.cn (J.W.); 15275188150@163.com (H.Q.); \\ lukechao178@163.com (K.L.); whzpcx@163.com (W.Z.) \\ 2 Jinan Foreign Language School, Jinan 250014, China; xzp020619@163.com \\ 3 Department of Mechanical \& Industrial Engineering, University of Toronto, 5 King's College Rd, Toronto, \\ Ontario M5S 3G8, Canada; xianjeremy.wang@mail.utoronto.ca \\ 4 School of Environmental Science \& Engineering, Qilu University of Technology (Shandong Academy of \\ Sciences), Jinan 250353, China; qingfeng@qlu.edu.cn \\ 5 College of information science and engineering, Shandong Agricultural University, Tai'an 271018, China \\ * Correspondence: liwang@qlu.edu.cn (L.W.); chenjun@qlu.edu.cn (J.C.); yanglei@sdau.edu.cn (L.Y.); \\ Tel./Fax: +86-0531-8963-1702 (L.W. \& J.C.); +86-0538-824-6257 (L.Y.) \\ + Authors are equally contributed.
}

Received: 4 October 2019; Accepted: 7 November 2019; Published: 9 November 2019

\begin{abstract}
Enrichment of cadmium ion $\left(\mathrm{Cd}^{2+}\right)$ from the environment may lead to kidney disease and weakened immunity in the body. Current techniques are not convenient enough to measure $\mathrm{Cd}^{2+}$ concentration in the environment due to low sensitivity and poor linear range. In this paper, a new measurement technique is proposed using a new sensing electrode made of nano-copper-enhanced carbon fiber. Nano-copper was deposited onto the surface of carbon fiber to enhance the current concentration and mass transfer rate of $\mathrm{Cd}^{2+}$ during measurement, which improved the electrochemical detection sensitivity significantly (by up to $3.7 \times 10^{8} \mathrm{nA} / \mathrm{nM}$ ) and broadened the linear range to $10 \sim 10^{5} \mathrm{nM}$. This device provides a low-cost solution for measuring $\mathrm{Cd}^{2+}$ concentration in the environment.
\end{abstract}

Keywords: cadmium ion; carbon fiber electrode; nano-copper; sensitivity for cadmium ion detection; charge transferability

\section{Introduction}

Heavy metal ions such as cadmium ions $\left(\mathrm{Cd}^{2+}\right)$ are highly toxic to human beings [1]. $\mathrm{Cd}^{2+}$ enrichment in human organs like kidney and bone can cause malfunctions in the metabolism of calcium and urine protein, and possibly lead to osteocarcinoma and kidney failure. In addition, cadmium is one of the major environmental pollutants in agricultural production and sanitation [2-5].

In the 1940s, serious cadmium-pollution-induced osteocarcinoma in Japan raised public awareness of cadmium's toxic effects for the first time [6,7]. Recently, another cadmium contamination event in the Longjiang River caused 2.8 million fish deaths and serious threats to human health nearby [8]. If a large number of people in an area get sick or die due to the contamination of cadmium, it is necessary to consider whether the cadmium concentration in the area is over the acceptable limit. Accordingly, a convenient method for measuring cadmium concentration is in great need.

To achieve this goal, many measuring methods for heavy metal ions have been developed [9]. Terahertz spectroscopy is one of the advanced techniques used. The sample is scanned by terahertz spectroscopy using electromagnetic radiation $(0.1 \mathrm{THz}$ to $10 \mathrm{THz})$ and characteristic absorption peaks 
appear at corresponding frequencies in the spectrum [10-12]. However, this technique is often used to measure caesium ions [13]. In fact, many different kinds of metal ions, including $\mathrm{Cd}^{2+}$, can cause a detrimental effect on the human body, which is out of the detectable range of elements in terahertz spectroscopy $[14,15]$. D'Auria's group invented a protein-bounded biosensor for cadmium detection. It achieved a high sensitivity of $2.5 \mu \mathrm{g} / \mathrm{mL} \sim 10 \mu \mathrm{g} / \mathrm{mL}$ and a lower detection limit of $0.5 \mu \mathrm{M}$. However, its performance highly depends on the temperature and $\mathrm{pH}$ conditions because the sensing part is a protein, i.e., metallothionein (MT) [16].

In recent years, electrochemical methods have become popular in detection of heavy metal ions due to advantages such as high sensitivity, simple procedures, and short analysis time [17]. Aswathi developed a sensor by depositing $\mathrm{MoS}_{2}$ onto a glassy carbon electrode (GCE) substrate, which achieved a detection performance of $\mathrm{Cd}^{2+}$ of $1.0 \times 10^{-12} \mathrm{~mol} / \mathrm{L}$ [18]. However, the contact area of the GCE (diameter $=3 \sim 5 \mathrm{~mm}$ ) was much larger than that of the micro-electrode, which was made of carbon fiber and had a diameter of $8 \mu \mathrm{m}$ [19]. This issue may reduce the analyte diffusion rate of the electrodes. As a result, GCE is not suitable for fast measurement of transient electrochemical reactions [20].

Recently, microelectrodes have been used for measuring heavy metal ions including $\mathrm{Cd}^{2+}$ [21]. For example, a gold-based microelectrode fabricated by microelectromechanical systems (MEMS) technology was used to measure $\mathrm{Cd}^{2+}$ in serum and achieved a sensitivity of $3.93 \mu \mathrm{A} / \mathrm{nM}$ [22]. A 64-microelectrode array can simultaneously measure $\mathrm{Cd}^{2+}$ and $\mathrm{Hg}^{2+}$ and reach a sensitivity of $28 \mathrm{nA} / \mathrm{nM}$ [23]. A new hybrid nanocomposite microelectrode was composed of one-dimensional multi-walled carbon nanotubes (MWCNTs) and two-dimensional graphene oxide flakes. This microelectrode improved the linear calibration range for $\mathrm{Pb}^{2+}$ and $\mathrm{Cd}^{2+}$ to $0.5-30 \mu \mathrm{g} / \mathrm{L}$ and the detection limits for $\mathrm{Cd}^{2+}$ to $0.61 \mathrm{nM}$ (signal-to-noise ratio $=3$, which is a threshold for evaluating effectiveness of the measured signal) [24]. Nanocomposite modification on electrode may improve the response time, sensitivity, and especially the linear sensing range and detection limit in $\mathrm{Cd}^{2+}$ measurement. Because the number of active electrons on the surface of the microelectrode could be increased and more chances to contact analytes would be created for electrochemical reactions [25].

In this paper, a carbon fiber modified with nano-copper deposition is used for $\mathrm{Cd}^{2+}$ detection. Optimal deposition times were tested experimentally and the results showed that a deposition time of $80 \mathrm{~s}$ could achieve the best sensitivity. In addition, the influence of $\mathrm{pH}$ was explored. The detection limit of the microelectrode after modification with nano-copper was improved to $10 \mathrm{nM}$. The sensitivity of the microelectrode was improved to $3.7 \times 108 \mathrm{nA} / \mathrm{nM}$. Finally, the proposed sensor was used to test water samples from a river, lake, and running water.

\section{Experimental Methods}

\subsection{Fabrication of the Carbon Fiber Electrode}

The preparation process of carbon fiber electrode is described as follows (Figure 1A): (1) A copper wire with a diameter of $100 \mu \mathrm{m}$ and a length of $70 \mathrm{~mm}$ was inserted into a glass tube (inner diameter = $1.1 \mathrm{~mm})$. (2) The glass tube was fixed by a holding device in the micromanipulator and the copper wire was welded to the carbon fiber using an electric soldering iron. The welded copper wire and carbon fiber were then moved to the centre of the glass tube. (3) The glass tube was calcined by the outer flame of the alcohol lamp. When the tube centre was melted by the flame, the glass tube broke up into two parts due to a preload force applied on its two terminals. (4) The carbon fiber was surrounded in the glass tube and formed a carbon fiber electrode. 
(A)
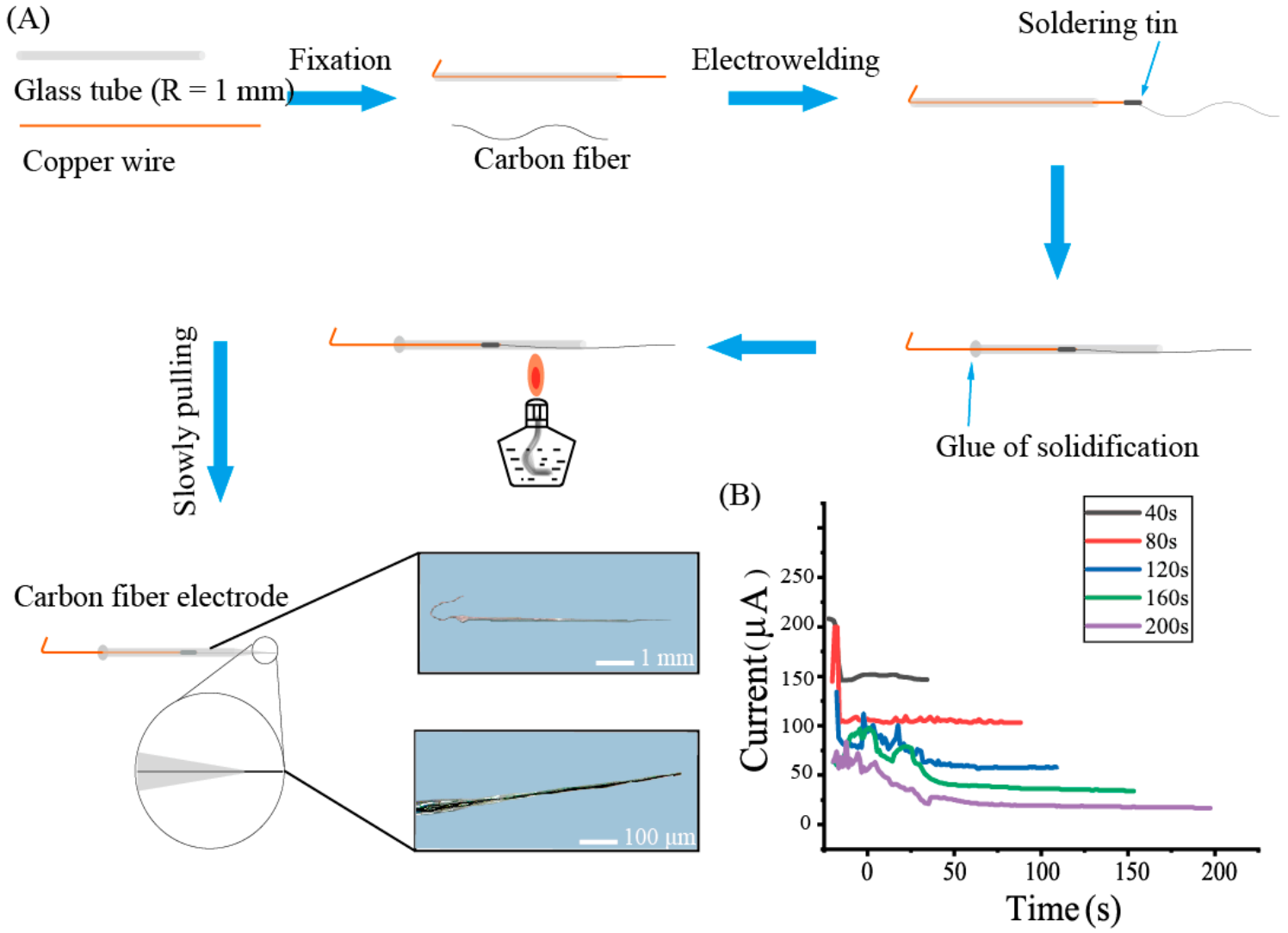

Figure 1. (A) A schematic for demonstrating each step during the fabrication process of the carbon fiber electrode. The digital images show a fabricated carbon fiber electrode and its tip shape. (B) The current change during the deposition of the nano-copper onto the surface of the carbon fiber.

\subsection{Nano-Copper Deposition and Electrochemical Measurements}

To enhance the electrochemical performance (e.g., sensitivity) of the carbon fiber microelectrode, nano-copper was deposited onto the surface of the carbon fibers by a potentiostatic method under different reaction conditions. First, a carbon fiber was sequentially washed using acetone, isopropanol and distilled water. After drying at $80^{\circ} \mathrm{C}$, the carbon fiber was cleaned using plasma for $30 \mathrm{~s}$ at the power of $50 \mathrm{~W} . \mathrm{CuSO}_{4}(0.3 \mathrm{~g})$ was dissolved in $20 \mathrm{~mL}$ of supporting electrolyte $(0.9 \% \mathrm{NaCl})$. The potentiostatic method was applied on an electrochemical work station (Metrohm-Autolab PGSTAT302N, Metrohm Autolab B.V., Utrecht, The Netherlands). A potential of $7.5 \mathrm{~V}$ was applied to the carbon fiber at room temperature. Six groups of reaction conditions (depositing time $=40 \mathrm{~s}, 80 \mathrm{~s}, 120 \mathrm{~s}, 160 \mathrm{~s}$, and $200 \mathrm{~s}$ ) were performed for the same type of carbon fibers, which aims to locate the proper depositing time for the optimal sensitivity of carbon fiber. After electrodeposition, the modified carbon fibers were washed with ethanol and distilled water in sequence to remove all loosely-bound nano-copper particles, and then dried in a vacuum at room temperature.

During measurement, the prepared electrode was placed in an electrochemical cell containing the analyte solution. The performance of the prepared electrochemical sensors was tested using analytical grade chemicals including $\mathrm{CdCl}_{2}, \mathrm{CuSO}_{4}, \mathrm{KCl}, \mathrm{HCl}$, and $\mathrm{NaOH}$, etc. Differential pulse voltammetry (DPV) and electrochemical impedance spectroscopy (EIS) were carried out on the electrochemical workstation (Metrohm-Autolab PGSTAT302N). The data were processed by using the softwares FRA and NOVA 1.11. The three-electrode system was used in all electrochemical experiments. $\mathrm{NaCl}$ solution $(0.9 \%)$ was used as the supporting solution. Two groups of electrodes including carbon fiber modified with and without nano-copper were used as the working electrode. $\mathrm{Ag} / \mathrm{AgCl}$ and platinum wires were used as the reference electrode and the counter electrode, respectively. Before each test, the surface of the carbon fiber was washed by cyclic voltammetry (CV) scanning for 300 cycles in a $0.9 \% \mathrm{NaCl}$ solution. 


\section{Results and Discussion}

\subsection{Exploration of Nano-Copper Modification Conditions on the Surface of Carbon Fiber}

\subsubsection{Modification of Nano-Copper on Carbon Fiber}

To observe the optimal performance of nano-copper, different depositing times (including $40 \mathrm{~s}$, $80 \mathrm{~s}, 120 \mathrm{~s}, 160 \mathrm{~s}$, and $200 \mathrm{~s}$ ) were explored. The anode current with different depositing times were recorded and plotted in Figure 1B, which showed that the anode current decreased from $150 \mu \mathrm{A}$ to $20 \mu \mathrm{A}$ at the end of each group. This indicates that the resistance decreased during the process of electrodeposition due to the accumulation of free electrons [26].

To determine the optimal electrodeposition condition, six groups of carbon fiber electrodes including a control group (the carbon fiber without nano-copper) were immersed in $\left[\mathrm{Fe}(\mathrm{CN})_{6}\right]^{3-}$ to test their DPV response. $\left[\mathrm{Fe}(\mathrm{CN})_{6}\right]^{3-}$ is commonly used as a bentchmark for evaluating the performance of electrochemical sensors. Figure 2a shows the DPV response of carbon fiber with and without nano-copper for $\left[\mathrm{Fe}(\mathrm{CN})_{6}\right]^{3-}$. The oxidation peak of the carbon fiber without nano-copper occurs at a potential of $35 \mathrm{mV}$ and its oxidation peak current is $1.96 \mathrm{nA}$. The difference between the peak current and background current is defined as $\Delta \mathrm{I}$, which refers to the first point of Figure $2 \mathrm{~b}$. The oxidation peak current dramatically increases to $4.1 \mathrm{nA}$ for the carbon fiber with nano-copper that was deposited under $40 \mathrm{~s}$, and the oxidation peak shifts to $7 \mathrm{mV}$. When the deposition time is increased to $80 \mathrm{~s}$, the oxidation peak current changes to $4.3 \mathrm{nA}$. However, the oxidation peak current decreases with the increase in deposition time, and its value decreases to $2.5 \mathrm{nA}(\Delta \mathrm{I}$ is $0.92 \mathrm{nA}$, shown in the sixth point of Figure $2 \mathrm{~b}$ ). From the DPV responses in the $\left[\mathrm{Fe}(\mathrm{CN})_{6}\right]^{3-}$ experiment, $80 \mathrm{~s}$ was selected as the deposition time for nano-copper modification.

\subsubsection{Characterization of Charge Transferability}

Electrochemical impedance spectroscopy (EIS) was adopted to verify the difference in charge transferability between the carbon fibers with and without nano-copper. Figure 2c shows Nyquist plots of the carbon fibers that were scanned in $5 \mathrm{mM}\left[\mathrm{Fe}(\mathrm{CN})_{6}\right]^{3+}$. The appearance of a semicircle in a Nyquist plot indicates that in the impedance model (see the inset in Figure 2c) there is a parallel connection between the resistor $R_{c t}$ (charge transfer resistance) and the capacitor $C_{\text {del }}$ (double electric layer). The calculated $R_{c t}$ in carbon fiber without nano-copper was $17.3 \mathrm{k} \Omega$ and that for carbon fiber with nano-copper was $6.5 \mathrm{k} \Omega$. A significant decrease $(62.4 \%)$ in $R_{c t}$ reveals that the nano-copper deposition is able to increase the electron transfer speed and enhance diffusion of reactive chemical species.

\subsubsection{Morphologies of Carbon Fibers with and without Nano-Copper}

To determine the mechanism of how the nano-copper deposition is able to enhance electrochemical sensing performance, the morphology change of carbon fiber before and after nano-copper modification was studied by SEM (S4800 microscope, Hitachi, Ltd. Hitachi, Japan). The inset in Figure 2b shows that carbon fiber without nano-copper has a smooth cylindrical surface, and its diameter is $7 \mu \mathrm{m}$. After depositing for $80 \mathrm{~s}$, rough nano-copper was evenly grown onto the surface of the carbon fiber and the diameter of the modified carbon fiber increased to $8.5 \mu \mathrm{m}$. The increased diameter and the roughness of the surface improved the specific surface area significantly, which provided more reaction sites for the bounding of the electrode and $\mathrm{Cd}^{2+}$. 
(a)

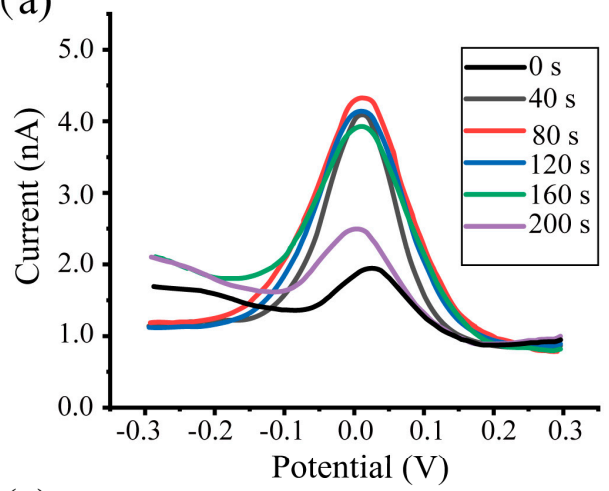

(c)

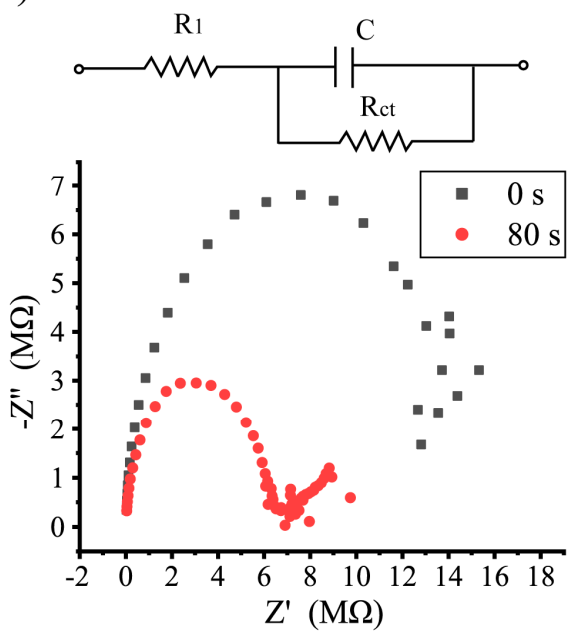

(b)

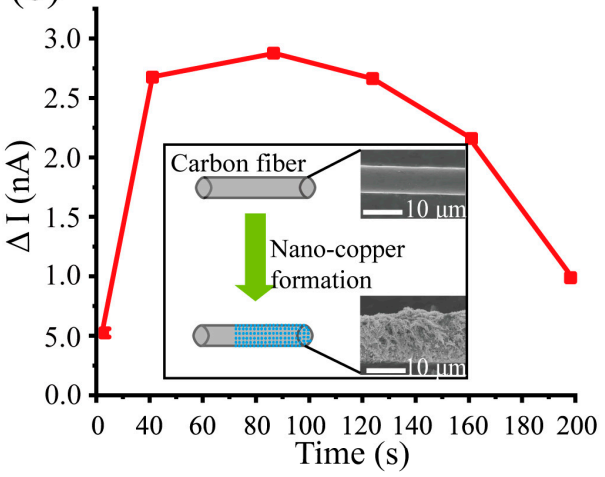

(d)

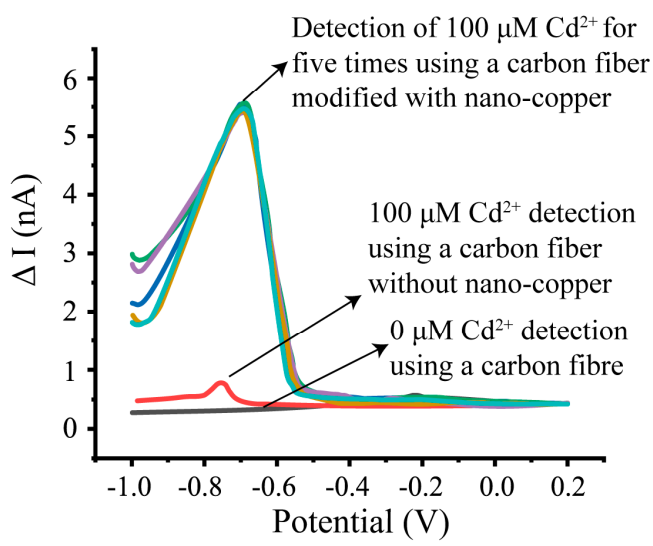

Figure 2. (a) Exploration of nano-copper modification conditions. Differential pulse voltammetry (DPV) responses of $5 \mathrm{mM}\left[\mathrm{Fe}(\mathrm{CN})_{6}\right]^{3-}$ using carbon fibers modified with different deposition times. (b) The measured $\Delta \mathrm{I}$ for different deposition times ( $\Delta \mathrm{I}$ was the largest with a deposition time of $80 \mathrm{~s}$ ). The SEM images of carbon fiber with and without nano-copper show significant surface morphology changes. (c) Verification of charge transferability by the electrochemical impedance spectroscopy (EIS) response for the carbon fibers with and without nano-copper ( $80 \mathrm{~s}$ and $0 \mathrm{~s}$, respectively). (d) DPV responses for $100 \mu \mathrm{M} \mathrm{Cd}^{2+}$ solution and supporting solution without $\mathrm{Cd}^{2+}$.

\subsection{DPV Response Comparison of the Carbon Fiber Electrode with and without Nano-Copper}

To compare the redox response of $\mathrm{Cd}^{2+}$ for the carbon fiber electrodes with and without nano-copper, DPV was employed to test a $100 \mu \mathrm{M} \mathrm{Cd}^{2+}$ solution group and another control group of solution without $\mathrm{Cd}^{2+}$. There was no oxidation peak (redox response did not occur) when carbon fiber electrodes were tested in the control group of solution without $\mathrm{Cd}^{2+}$. For the carbon fiber electrode without nano-copper, there was an oxidation peak at a potential of $-751 \mathrm{mV}$ with a value of $0.82 \mathrm{nA}$. However, the oxidation peak current increased to $5.6 \mathrm{nA}$ for the carbon fiber electrode with nano-copper and the potential of the oxidation peak shifted to $-696 \mathrm{mV}$. The significant improvement of the DPV response may be attributed to the enlarged specific surface area and more reaction contacting spots after nano-copper deposition [27].

In addition, the DPV measurement for the carbon fiber with nano-copper was repeated for five times to test its stability. It can be seen from Figure $2 \mathrm{~d}$ that the peak current stabilized around $5.6 \mathrm{nA}$. This indicates that the electrode can achieve a steady response output for $\mathrm{Cd}^{2+}$ detection. 


\subsection{The Influence of $p H$}

It is well accepted that the $\mathrm{pH}$ of the aqueous solution would affect the electrocatalytic reaction in the electrochemical redox process [28]. Thus, the influence of $\mathrm{pH}$ on detecting $\mathrm{Cd}^{2+}$ was investigated for the carbon-fiber-modified electrode (Figure 3a). The $\mathrm{pH}$ changed from 2.7 to 6.6 and the $\Delta \mathrm{I}$ was used to compare the influence of $\mathrm{pH}$. The $\Delta \mathrm{I}$ slowly increased when the $\mathrm{pH}$ changed from 2.7 to 5.9 . When the $\mathrm{pH}$ achieved a value of 6.1 , the $\Delta \mathrm{I}$ increased to the maximum level ( $3.25 \mathrm{nA}$ ). After this, the $\Delta \mathrm{I}$ started to decrease. Therefore, $\mathrm{pH}=6.1$ was selected for testing $\mathrm{Cd}^{2+}$.
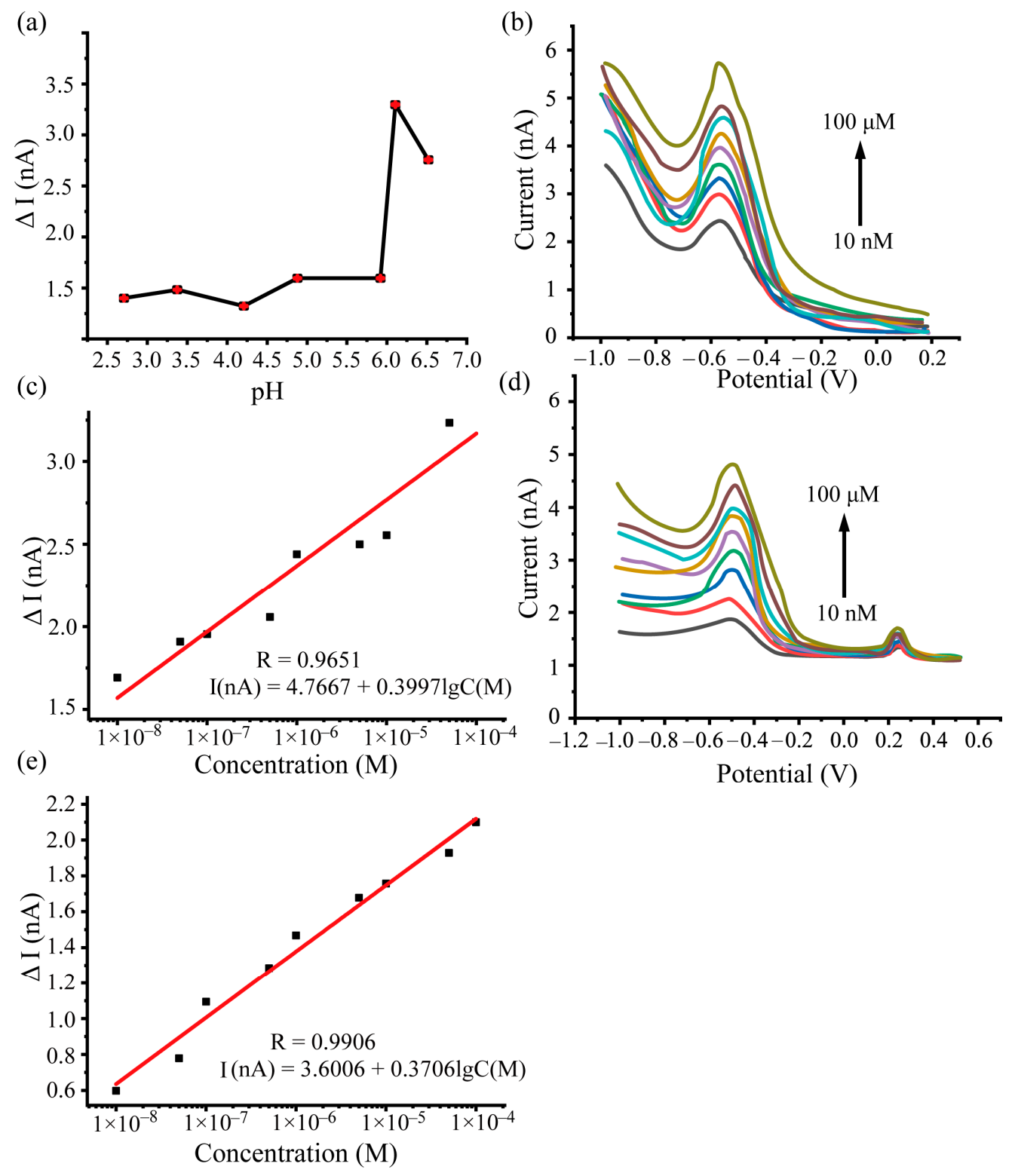

Figure 3. (a) The influence of $\mathrm{pH}$ in the DPV response for $\mathrm{Cd}^{2+}$. The $\mathrm{pH}$ was changed from 2.7 to 6.6. (b) DPV responses of nano-copper-modified carbon fiber with different concentrations of $\mathrm{Cd}^{2+}$ from $10 \mathrm{nM}$ to $100 \mu \mathrm{M}$. (c) The fitting result between $\Delta \mathrm{I}$ (the difference between the peak current and background current) and the concentration of $\mathrm{Cd}^{2+} ; \Delta \mathrm{I}=\mathrm{k} \lg (\mathrm{C})+\mathrm{b}$. (d) The DPV responses for the mixing of foreign ions including $\mathrm{K}^{+}, \mathrm{Na}^{+}, \mathrm{Cu}^{2+}, \mathrm{Hg}^{2+}, \mathrm{Al}^{3+},\left(\mathrm{SO}_{4}\right)^{2-}$, and $\left(\mathrm{NO}_{3}\right)^{-}$. (e) The fitting result between $\Delta \mathrm{I}$ and the concentration of $\mathrm{Cd}^{2+}$ in the presence of foreign ions. 


\subsection{Determination of the Sensitivity, Detection Limit, and Linear Range for $\mathrm{Cd}^{2+}$ Measurement}

To evaluate the performance including the linear range, sensitivity and detection limit of the proposed carbon fiber electrode, $\mathrm{Cd}^{2+}$ solutions from $10 \mathrm{nM}$ to $100 \mu \mathrm{M}$ was used as the testing sample. Figure $3 b$ shows that the oxidation current increases with the concentration of $\mathrm{Cd}^{2+}$. When $\mathrm{Cd}^{2+}$ concentration is less than $1 \mathrm{nM}$ and $5 \mathrm{nM}$ in the supporting solution, there is no detectable current response. When the $\mathrm{Cd}^{2+}$ concentration is increased to $10 \mathrm{nM}$, an oxidation peak was detected (signal-to-noise ratio $>3$ ) which is referred as the detection limit of the carbon fiber electrode for $\mathrm{Cd}^{2+}$. The specific values of oxidized peak currents were evaluated and were linear fitted with the $\log$ concentration of $\mathrm{Cd}^{2+}$ in the form $\Delta \mathrm{I}=\mathrm{k} \lg (\mathrm{C})+\mathrm{b}$. The fitting result (see Figure $3 \mathrm{c}$ ) shows that the sensitivity of carbon fiber with nano-copper for $\mathrm{Cd}^{2+}$ is $0.3997 \mathrm{nA} / \mathrm{nM}$ and that the linear range is the whole detection range $(10 \mathrm{nM}$ to $100 \mu \mathrm{M})$. In addition, the $\mathrm{Cd}^{2+}$ sensing performance of our nano-copper-modified carbon fiber electrode and other electrodes in the literature are compared in Table 1, which shows that the proposed electrodes have superiority in the detection limit and the linear range.

Table 1. Comparison of $\mathrm{Cd}^{2+}$ sensing performance among our nano-copper-modified carbon fiber electrode and other electrodes in the literature.

\begin{tabular}{|c|c|c|c|c|c|}
\hline Electrode Type & $\begin{array}{l}\text { Detection } \\
\text { Limit (nM) }\end{array}$ & $\begin{array}{l}\text { Sensitivity } \\
\text { (nA/nM) }\end{array}$ & $\begin{array}{l}\text { Linear Range } \\
\text { (nM) }\end{array}$ & $\begin{array}{l}\text { Detection } \\
\text { Method }\end{array}$ & Reference \\
\hline $\begin{array}{l}\text { GCE modified with CNT/poly } \\
\text { pyrocatechol violet/bismuth }\end{array}$ & 1.22 & 1.7 & $6.08 \sim 1820$ & ASV & [29] \\
\hline $\begin{array}{l}\text { N-doped carbon quantum } \\
\text { dots-graphene oxide (NCQDs-Go)/GCE }\end{array}$ & 45.3 & 0.16 & $0.67 \sim 683.6$ & ASV & {$[30]$} \\
\hline $\begin{array}{l}\text { GCE modified with gold } \\
\text { nanoparticles(AuNPs) }\end{array}$ & 0.045 & / & $0.0017 \sim 16.7$ & Colorimetri & {$[31]$} \\
\hline $\mathrm{Mo}_{6} \mathrm{~S}_{9} / \mathrm{GCE}$ & 0.61 & 260 & $3.04 \sim 912$ & DPASV & [32] \\
\hline $\begin{array}{c}\text { Nanocomposite based on } \\
\text { nanographene }\end{array}$ & 0.023 & 405 & $1.52 \sim 30.4$ & DPASV & {$[33]$} \\
\hline $\begin{array}{c}\text { Covalent anchoring of aryldiazonium } \\
\text { salt }\end{array}$ & 2.2 & $8.83 \times 10^{6}$ & $25 \sim 500$ & SWASV & {$[34]$} \\
\hline $\begin{array}{l}\text { Bi doped mesoporous } \\
\text { carbonxerogel/(GCE) }\end{array}$ & 308 & $2.67 \times 10^{6}$ & $6810 \sim 7540$ & SWASV & [35] \\
\hline GCE modified with MWCNT & 2.3 & / & / & EIS & [36] \\
\hline Bismuth nanorib bons(BiNRs) sensor & 0.88 & $1.2 \times 10^{6}$ & $6.08 \sim 304$ & DPASV & [37] \\
\hline $\begin{array}{l}\text { Au-Ph-AuNP-glutathione(GSH) } \\
\text { electrode }\end{array}$ & 0.01 & $9.17 \times 10^{7}$ & $0.1 \sim 10$ & OsWV & [38] \\
\hline $\begin{array}{l}\text { Bismuthnanoparticle-porous/carbon } \\
\text { paste electrode(CPE) }\end{array}$ & 4.93 & $1.22 \times 10^{6}$ & $6.08 \sim 608$ & SWASV & [39] \\
\hline $\begin{array}{c}\text { Carbon fibre electrode modified with } \\
\text { nano-copper }\end{array}$ & 10 & $3.7 \times 10^{8}$ & $10 \sim 10^{5}$ & DPV & This work \\
\hline
\end{tabular}

\subsection{The Selectivity of the Carbon Fiber Electrode with Nano-Copper}

To determine the selectivity of our electrode, the DPV response was tested in the supporting solution with foreign ions, including $500 \mu \mathrm{M} \mathrm{K}^{+}, \mathrm{Na}^{+}, \mathrm{Cu}^{2+}, \mathrm{Hg}^{2+}, \mathrm{Al}^{3+},\left(\mathrm{SO}_{4}\right)^{2-}$, and $\left(\mathrm{NO}_{3}\right)^{-}$. The amount of foreign ions was five-fold to $50,000-$ fold that of $\mathrm{Cd}^{2+}$. Figure $3 \mathrm{~d}$ shows the DPV response for the mixed solutions. During the voltage scanning range (from $-1.1 \mathrm{~V}$ to $0.5 \mathrm{~V}$ ), obvious oxidation peaks occur around a potential of $224 \mathrm{mV}$. This is probably due to the presence of $\mathrm{Hg}^{2+}$, according to the reported results in the literature $[26,40]$.

There is also an inconspicuous peak around the potential of $-300 \mathrm{mV}$, which may be the response of $\mathrm{Cu}^{2+}$. However, the peak is mostly covered by the DPV response of $\mathrm{Cd}^{2+}$. The results reveal that foreign ions have little effect on $\mathrm{Cd}^{2+}$ detection.

In addition, it was evaluated whether the foreign ions affect the linear range, sensitivity, and detection limit of the proposed carbon fiber electrode. The curve between $\mathrm{Cd}^{2+}$ concentration and DPV peak current was fitted (see Figure 3e). This indicated that the linear range and the detection limit did not change when the interference was presented while the sensitivity was slightly decreased by $7.28 \%$. 


\subsection{Analytical Application to Water Samples Collected from Water Sources}

To verify the performance of our carbon fiber electrode sensor for $\mathrm{Cd}^{2+}$ detection, water samples collected from water sources around Jinan city, including the Daming Lake, the Black Tiger Spring, the Xioaqing River, the Yellow River, and the Changqing Lake. Figure 4 shows the DPV responses of these water samples with $\mathrm{pH}=6.1$. Their corresponding $\mathrm{Cd}^{2+}$ concentrations are shown in the diagram in Figure $4 b$, which was obtained from the curve fitting result in Section 3.5. According to the World Health Organization (WHO) guidelines for drinking water quality, cadmium ion concentration must be less than $0.005 \mathrm{mg} / \mathrm{L}(0.3 \mu \mathrm{M})$. Otherwise, the cadmium ion would be a threat to the health of the kidneys and other organs. The results revealed that the water in Daming Lake was not suitable for drinking directly.

(a)

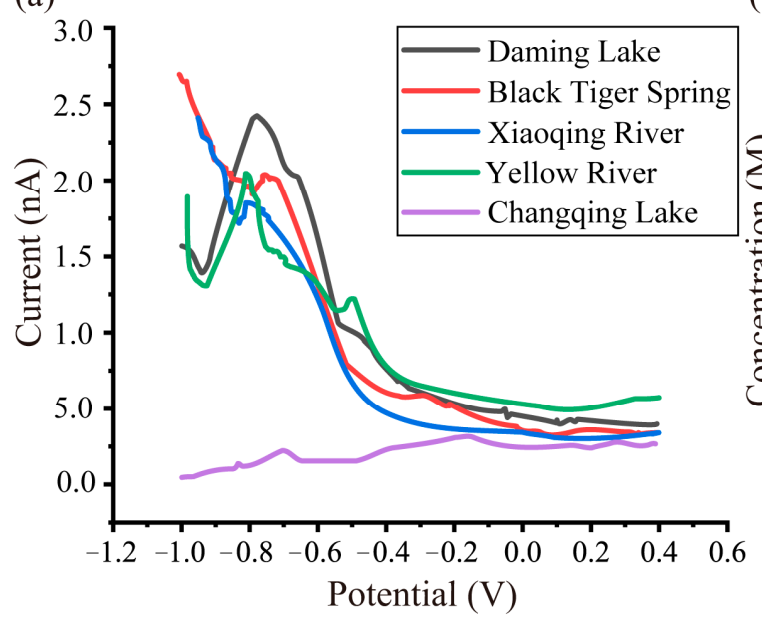

(b)

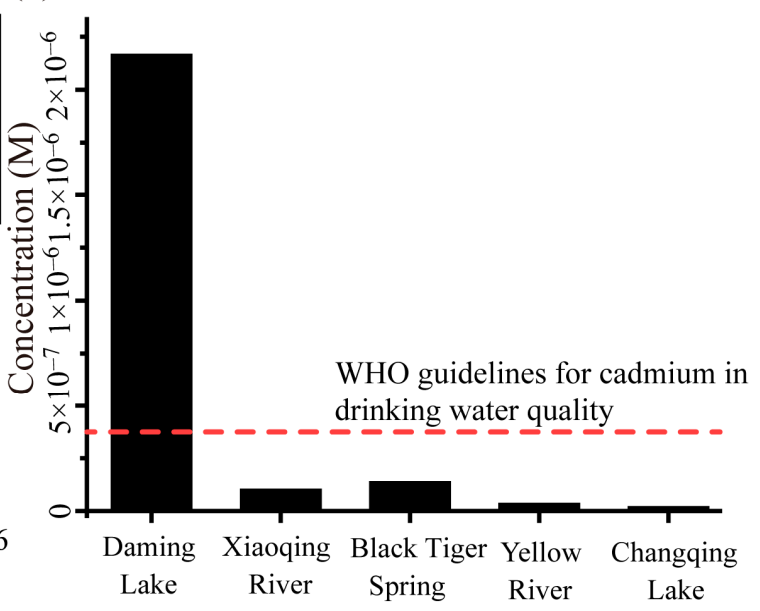

Figure 4. Water samples collected from several typical water sources around Jinan city (including the Daming Lake, the Black Tiger Spring, the Xiaoqing River, the Yellow River, and the Changqing Lake) were measured using the proposed carbon fiber electrode with nano-copper. (a) The DPV responses of the water samples. (b) The diagram for the $\mathrm{Cd}^{2+}$ concentration results of the water samples and their comparison with the suggested concentration given by the World Health Organization (WHO).

\section{Conclusions}

In this study, a nano-copper-modified carbon fiber electrode was proposed and applied for $\mathrm{Cd}^{2+}$ inspection in drinking water. The detection limit, linear range, sensitivity and selectivity of the proposed sensor were justified. DPV technology was used to record the currents generated by the metal ions. The performance of the proposed carbon fiber electrode was also verified by measuring $\mathrm{Cd}^{2+}$ concentrations of water samples collected from water sources. The experiment results indicated that nano-copper deposition played a crucial rule in the improvement of the sensitivity of the electrode and the attraction ability for $\mathrm{Cd}^{2+}$ ions.

Based on the results from this study, the next step for this sensor would be to integrate it into a portable device and apply it to the monitoring of the enrichment of heavy metal ions in the human body. The measuring results of $\mathrm{Cd}^{2+}$ concentrations could be sent to mobile phones by Bluetooth.

Author Contributions: Conceptualization, J.W. and Z.X.; methodology, K.L. and Q.F.; software, H.Q. and X.W.; validation, L.W., J.C. and L.Y.; formal analysis, J.W.; investigation, Z.X.; resources, L.W., J.C. and L.Y.; data curation, W.Z.; writing-original draft preparation, J.W. and Z.X.; writing-review and editing, L.W., J.C. and L.Y.; project administration, L.W., J.C. and L.Y.; funding acquisition, L.W., J.C. and L.Y.

Acknowledgments: The authors acknowledge the financial support of the National Natural Science Fund of China (grant nos. 31971781 and 61901239) and the Taishan Scholars Young Expert (no. tsqn201812087). Li Wang thanks the guidance of his postdoctoral advisor Professor Yu Sun (University of Toronto) and his Ph.D advisor Professor Xinxia Cai (Institute of Electronics, Chinese Academy of Sciences).

Conflicts of Interest: The authors declare no conflict of interest. 


\section{References}

1. Tchounwou, P.B.; Yedjou, C.G.; Patlolla, A.K.; Sutton, D.J. Heavy Metal Toxicity and the Environment, Chapter in: Molecular, Clinical and Environmental Toxicology; Luch, A., Ed.; Springer: Berlin/Heidelberg, Germany, 2012; Volume 3, pp. 133-164.

2. Singh, R.; Gautam, N.; Mishra, A.; Gupta, R. Heavy metals and living systems: An overview. Indian J. Pharmacol. 2011, 43, 246-253. [CrossRef] [PubMed]

3. Rather, I.A.; Koh, W.Y.; Paek, W.K.; Lim, J. The sources of chemical contaminants in food and their health implications. Front. Pharmacol. 2017, 8, 830. [CrossRef] [PubMed]

4. Li, X.F. Technical solutions for the safe utilization of heavy metal-contaminated farmland in China: A critical review. Land Degrad. Dev. 2019, 30, 1773-1784. [CrossRef]

5. Wang, L.; Cui, X.; Cheng, H.; Chen, F.; Wang, J.; Zhao, X.; Lin, C.; Pu, X. A review of soil cadmium contamination in China including a health risk assessment. Environ. Sci. Pollut. Res. 2015, 22, 16441. [CrossRef]

6. Rahimzadeh, M.R.; Rahimzadeh, M.R.; Kazemi, S.; Moghadamnia, A.A. Cadmium toxicity and treatment: An update. Casp. J. Intern. Med. 2017, 8, 135-145.

7. Huff, J.; Lunn, R.M.; Waalkes, M.P.; Tomatis, L.; Infante, P.F. Cadmium-induced cancers in animals and in humans. Int. J. Occup. Environ. Health 2007, 13, 202-212. [CrossRef]

8. Ahmed, F.E.; Taylor, S.L.; Committee on Evaluation of the Safety of Fishery Products. Seafood Safety; National Academy Press: Washington, DC, USA, 1991.

9. Gumpu, M.B.; Sethuraman, S.; Krishnan, U.M.; Rayappan, J.B.B. A review on detection of heavy metal ions in water-An electrochemical approach. Sens. Actuators B Chem. 2015, 213, 515-533. [CrossRef]

10. Dhillon, S.S.; Vitiello, M.S.; Linfield, E.H.; Davies, A.G.; Hoffmann, M.C.; Booske, J.; Paoloni, C.; Gensch, M.; Weightman, P.; Williams, G.P.; et al. The 2017 terahertz science and technology roadmap. J. Phys. D Appl. Phys. 2017, 50, 043001. [CrossRef]

11. Yasui, T.; Ichikawa, R.; Hsieh, Y.D.; Hayashi, K.; Cahyadi, H.; Hindle, F.; Sakaguchi, Y.; Iwata, T.; Mizutani, Y.; Yamamoto, H.; et al. Adaptive sampling dual terahertz comb spectroscopy using dual free-running femtosecond lasers. Sci. Rep. 2015, 5, 1-10. [CrossRef]

12. Yeo, W.G. Terahertz Spectroscopic Characterization and Imaging for Biomedical Applications. Ph.D. Thesis, Ohio State University, Columbus, OH, USA, 2015.

13. ATSDR. Toxicological Profile for Cesium; Case Studies in Environmental Medicine; Agency for Toxic Substances and Disease Registry: Atlanta, GA, USA, 2004.

14. Ganrot, P. Metabolism and possible health effects of aluminum biochemistry and metabolism of A13+ and similar ions: A Review. Environ. Health Perspect. 1986, 65, 363-441.

15. Peterson, J.; MacDonell, M.; Haroun, L.; Monette, F.; Hildebrand, R.D.; Taboas, A. Radiological and Chemical Fact Sheets to Support Health Risk Analyses for Contaminated Areas; Argonne National Laboratory Environmental Science Division: Washington, DC, USA, 2007; Volume 133.

16. Varriale, A.; Staiano, M.; Rossi, M.; D'Auria, S. High-affinity binding of cadmium ions by mouse metallothionein prompting the design of a reversed-displacement protein-based fluorescence biosensor for cadmium detection. Anal. Chem. 2007, 79, 5760-5762. [CrossRef] [PubMed]

17. Zhu, C.; Yang, G.; Li, H.; Du, D.; Lin, Y. Electrochemical sensors and biosensors based on nanomaterials and nanostructures. Anal. Chem. 2015, 87, 230-249. [CrossRef] [PubMed]

18. Aswathi, R.; Sandhya, K.Y. Ultrasensitive and selective electrochemical sensing of $\mathrm{Hg}$ (II) ions in normal and sea water using solvent exfoliated MoS2: Affinity matters. J. Mater. Chem. A 2018, 6, 14602-14613. [CrossRef]

19. Sapountzi, E.; Braiek, M.; Chateaux, J.F.; Jaffrezic-Renault, N.; Lagarde, F. Recent advances in electrospun nanofibre interfaces for biosensing devices. Sensors. 2017, 17, 1887. [CrossRef]

20. Lohse, K.R.; Lang, C.E.; Boyd, L.A. Is more better? Using metadata to explore dose-response relationships in stroke rehabilitation. Stroke 2014, 45, 2053-2058. [CrossRef]

21. Piñeros, M.A.; Shaff, J.E.; Kochian, L.V. Development, characterization, and application of a cadmium-selective microelectrode for the measurement of cadmium fluxes in roots of thlaspi species and wheat. Plant Physiol. 1998, 116, 1393-1401. [CrossRef] 
22. Xuan, X.; Park, J.Y. A miniaturized and flexible cadmium and lead ion detection sensor based on micro-patterned reduced graphene oxide/carbon nanotube/bismuth composite electrodes. Sens. Actuators B Chem. 2018, 255, 1220-1227. [CrossRef]

23. Mastouri, A.; Peulon, S.; Farcage, D.; Bellakhal, N.; Chaussé, A. Perfect additivity of microinterface arrays for liquid-liquid measurements: Application to cadmium ions quantification. Electrochim. Acta 2014, 120, 212-218. [CrossRef]

24. Huang, H. Electrochemical Application and AFM Characterization of Nanocomposites: Focus on Interphase Properties. Ph.D. Thesis, Shandong University, Jinan, China, 2017.

25. Yang, D.; Wang, L.; Chen, Z.; Megharaj, M.; Naidu, R. Voltammetric determination of lead (II) and cadmium (II) using a bismuth film electrode modified with mesoporous silica nanoparticles. Electrochim. Acta 2014, 132, 223-229. [CrossRef]

26. Shah, A.; Sultan, S.; Zahid, A.; Aftab, S.; Nisar, J.; Nayab, S.; Qureshi, R.; Khan, G.S.; Hussain, H.; Ozkan, S.A. Highly sensitive and selective electrochemical sensor for the trace level detection of mercury and cadmium. Electrochim. Acta 2017, 258, 1397-1403. [CrossRef]

27. Rahbar, N.; Parham, H. Carbon paste electrode modified with cuo-nanoparticles as a probe for square wave voltammetric determination of atrazine. Jundishapur J. Nat. Pharm. Prod. 2013, 8, 118-124. [CrossRef] [PubMed]

28. Wang, J.; Yang, B.; Gao, F.; Song, P.; Li, L.; Zhang, Y.; Lu, C.; Goh, M.C.; Du, Y. Ultra-stable electrochemical sensor for detection of caffeic acid based on platinum and nickel jagged-like nanowires. Nanoscale Res. Lett. 2019, 14, 11. [CrossRef] [PubMed]

29. Chamjangali, M.A.; Kouhestani, H.; Masdarolomoor, F.; Daneshinejad, H. A voltammetric sensor based on the glassy carbon electrode modified with multi-walled carbon nanotube/poly (pyrocatechol violet)/bismuth film for determination of cadmium and lead as environmental pollutants. Sens. Actuators B Chem. 2015, 216, 384-393. [CrossRef]

30. Li, L.; Liu, D.; Shi, A.; You, T. Simultaneous stripping determination of cadmium and lead ions based on the N-doped carbon quantum dots-graphene oxide hybrid. Sens. Actuators B Chem. 2018, 255, 1762-1770. [CrossRef]

31. Li, L.; Liu, B.; Chen, Z. Colorimetric and dark-field microscopic determination of cadmium(II) using unmodified gold nanoparticles and based on the formation of glutathione-cadmium(II) complexes. Microchim. Acta 2019, 186, 7-13. [CrossRef] [PubMed]

32. Lin, H.; Li, M.; Mihailovič, D. Simultaneous determination of copper, lead, and cadmium ions at a Mo6S9-xIx nanowires modified glassy carbon electrode using differential pulse anodic stripping voltammetry. Electrochim. Acta 2015, 154, 184-189. [CrossRef]

33. Wu, L.; Fu, X.; Liu, H.; Li, J.; Song, Y. Comparative study of graphene nanosheet-and multiwall carbon nanotube-based electrochemical sensor for the sensitive detection of cadmium. Anal. Chim. Acta 2014, 851, 43-48. [CrossRef]

34. Cui, L.; Wu, J.; Ju, H. Nitrogen-doped porous carbon derived from metal-organic gel for electrochemical analysis of heavy-metal ion. ACS Appl. Mater. Interfaces 2014, 6, 16210-16216. [CrossRef]

35. Fort, C.I.; Cotet, L.C.; Vulpoi, A.; Turdean, G.L.; Danciu, V.; Baia, L.; Popescu, I.C. Bismuth doped carbon xerogel nanocomposite incorporated in chitosan matrix for ultrasensitive voltammetric detection of $\mathrm{Pb}$ (II) and Cd (II). Sens. Actuators B Chem. 2015, 220, 712-719. [CrossRef]

36. Wardak, C. Solid contact cadmium ion-selective electrode based on ionic liquid and carbon nanotubes. Sens. Actuators B Chem. 2015, 209, 131-137. [CrossRef]

37. Devasenathipathy, R.; Karthik, R.; Chen, S.M.; Mani, V.; Vasantha, V.S.; Ali, M.A.; Elshikh, M.S.; Lou, B.S.; Al-Hemaid, F.M.A. Potentiostatic electrochemical preparation of bismuth nanoribbons and its application in biologically poisoning lead and cadmium heavy metal ions detection. Electroanalysis 2015, 27, 2341-2346. [CrossRef]

38. Liu, G.; Zhang, Y.; Qi, M.; Chen, F. Covalent anchoring of multifunctionized gold nanoparticles on electrodes towards an electrochemical sensor for the detection of cadmium ions. Anal. Methods 2015, 7, 5619-5626. [CrossRef] 
39. Niu, P.; Fernández-Sánchez, C.; Gich, M.; Ayora, C.; Roig, A. Electroanalytical assessment of heavy metals in waters with bismuth nanoparticle-porous carbon paste electrodes. Electrochim. Acta 2015, 165, $155-161$. [CrossRef]

40. Budnikova, Y.H.; Krasnov, S.A.; Magdeev, I.M.; Sinyashin, O.G. Laws of chloride-ions oxidation on various electrodes and “Green" electrochemical method of higher $\alpha$-Olefins processing. ECS Trans. 2010, 25, 7-15. 